\title{
Investigation of the Structural and Magnetic Properties of the Cobalt-Nickel Alloys Fabricated in Various Electrolyte Solutions
}

\author{
R. ÖZDEMIR ${ }^{a, *}$, C.A. KORKMAZ ${ }^{b}$ AND İ.H. KARAHAN ${ }^{c}$ \\ ${ }^{a}$ Kilis 7 Aralik University, Vocational High School, Kilis, Turkey \\ ${ }^{b}$ Kilis 7 Aralik University, Department of Physics, Kilis, Turkey \\ ${ }^{c}$ Mustafa Kemal University, Department of Physics, Hatay, Turkey
}

\begin{abstract}
Cobalt-Nickel alloys have been widely used for decoration, in magnetic recording devices and corrosion resistance applications, etc. In this study, the influences of cobalt amount in electrolyte on the magnetic and structural properties of the electrodeposited Co-Ni alloys were investigated. An electrolyte solution, consisting of cobalt sulfate, nickel sulfate, nickel chloride and boric acid, was used in electrodeposition. The electrochemical investigation of Co-Ni alloys was completed using cyclic voltammetry and galvanostatic studies. The morphological and structural analyses of the alloys were performed using inductively coupled plasma, scanning electron microscopy, $\mathrm{X}$-ray diffraction and vibrating sample magnetometer techniques. The effect of cobalt concentration on the magnetic properties, phase structure and grain size of the alloys was investigated. Magnetic hysteresis results indicate that the amount of the cobalt content in the electrolyte has a strong influence on the ferromagnetic behavior of fabricated alloys. Results of the study show that changing the electrodeposition parameters, such as composition of electrolyte solution, allows to fabricate alloys with different properties.
\end{abstract}

DOI: 10.12693/APhysPolA.132.1045

PACS/topics: 81.05.Bx, 81.40.Rs, 81.15.Pq, 82.45.Qr

\section{Introduction}

Co-Ni alloys have been widely studied in recent years due to their unique physical and chemical properties $[1,2]$. It has been reported that Co-Ni coatings display high adhesion, heat-conductivity, thermal stability, corrosion resistance, mechanical, chemical and also superior magnetic properties [3-5]. Co-Ni coatings could be used as soft magnetic materials and shape memory alloys [6].

It is known that Co-Ni alloys have excellent magnetic properties. $\mathrm{Co}-\mathrm{Ni}$ alloys have superior permanent magnetic properties than the pure metals [7]. Additionally, changing composition of the magnetic alloys offers a way of modification of their magnetic properties, such as controllable coercivity and improved saturation magnetization [7].

Various methods can be used for the deposition of coatings, such as sputtering [8], vapor deposition [9], spin coating and electrodeposition [10-12]. Nonetheless, with the exception of electrodeposition, these methods are not effective for creation of coatings of high quality and well controlled magnetic layers [13].

Electrodeposition is a coating method with many practical advantages, such as ability to coat complex geometries, low operation temperature, and control of coating composition [14]. Electrodeposition method has been widely used for fabrication of $\mathrm{Co}-\mathrm{Ni}$ coatings due to

*corresponding author; e-mail: rsmozdemir@gmail.com anomalous codeposition behavior of these elements [15]. Electrodeposited Co-Ni alloys have high hardness, excellent wear and corrosion resistance, anti-corrosion, heat-conductive, magnetic, and electrocatalytic properties $[16,17]$.

It is known that properties of the electrodeposited coatings are affected by such deposition parameters as the electrolyte composition, electrolyte $\mathrm{pH}$, applied potential and current, temperature and substrate material [1820]. Variation of the experimental parameters can lead to deposition of alloys with different composition, surface morphology, and magnetic properties. Recent studies indicate that magnetic properties of $\mathrm{Co}-\mathrm{Ni}$ alloys can be controlled via modificaton of structural properties [21].

The aim of this study is to investigate the effect of the Co content in electrolyte, as an electrodeposition parameter, on the elemental composition, structure, morphology, electrochemical and magnetic properties of the Co-Ni alloys.

\section{Experimental}

Commercially provided aluminum sheets were used as substrates. Al substrate allows to easily stripe the deposited Co-Ni alloys from surface, to protect the coating from the influence of the aluminum in further analyzes. Prior to electrodeposition, Al substrates were polished and dipped into $1 \mathrm{M} \mathrm{NaOH}$ at $70^{\circ} \mathrm{C}$ for $5 \mathrm{~min}$, to etch the surface, and cleaned with ultrapure water. All electrolyte solutions were prepared from reagent grade chemicals and ultrapure water. A saturated calomel electrode (SCE) and a platinum wire were used as the reference and the counter electrodes, respectively. 
Cyclic voltammetry (CV) studies were performed to determine appropriate potential and current values and to determine reaction of the substrate under the positive and negative polarizations, for each electrolyte solution. A $10 \mathrm{mV} \mathrm{s}^{-1}$ potential scan was carried out between $0.5 \mathrm{~V}$ (initial voltage) and $-1.6 \mathrm{~V}$ and ended at $0.5 \mathrm{~V}$. All potential values in electrochemical experiments were recorded versus SCE.

Co-Ni alloys were deposited galvonostatically onto $\mathrm{Al}$ substrates with a surface area of $2.9 \times 10^{-4} \mathrm{~m}^{2}$. A current of $50 \mathrm{~mA}$, corresponding to current density of $173 \mathrm{~A} \mathrm{~m}^{-2}$ was applied in electrodeposition experiments. Solution $\mathrm{pH}$ was adjusted to 4.5 by $1 \mathrm{M} \mathrm{HCl}$ and $10 \% \mathrm{NaOH}$ solutions (Hanna Scientific pH-meter). All electrolyte solutions were stirred during deposition, to maintain the homogeneity of the solutions. Temperature was kept constant at $50^{\circ} \mathrm{C}$.

To understand the effect of Co amount in the solution, four different electrolyte solutions were prepared, having different concentrations of Co from 0.04 to $0.10 \mathrm{M}$. The experimental parameters of electrochemical deposition and electrolyte compositions, used to fabricate the coatings, are shown in Table I. After completing electrodeposition $\mathrm{Co}-\mathrm{Ni}$ coatings were removed from aluminum substrate for further analyzes.

TABLE I

Bath conditions of the $\mathrm{Co}_{1-x} \mathrm{Ni}_{x}$ alloys electrodeposition.

\begin{tabular}{|c|c|c|c|c|c|c|}
\hline \multirow[b]{2}{*}{$\mathrm{SN}$} & \multicolumn{4}{|c|}{ Electrolyte in materials $\left[\mathrm{Moll}^{-1}\right]$} & \multirow[b]{2}{*}{$\begin{array}{l}\text { Temp. } \\
{\left[{ }^{\circ} \mathrm{C}\right]}\end{array}$} & \multirow[b]{2}{*}{$\mathrm{pH}$} \\
\hline & $\begin{array}{l}\mathrm{NiSO}_{4} \\
\cdot 6 \mathrm{H}_{2} \mathrm{O}\end{array}$ & $\begin{array}{l}\mathrm{NiCl}_{2} \\
.6 \mathrm{H}_{2} \mathrm{O}\end{array}$ & $\mathrm{H}_{3} \mathrm{BO}_{3}$ & $\begin{array}{l}\mathrm{CoSO}_{4} \\
\cdot 7 \mathrm{H}_{2} \mathrm{O}\end{array}$ & & \\
\hline $\mathrm{Co}_{52}$ & 0.10 & 0.20 & 0.25 & 0.04 & 50 & 0.45 \\
\hline $\mathrm{Co}_{64} \mathrm{Ni}_{36}$ & 0.10 & 0.20 & 0.25 & 0.06 & 50 & 0.45 \\
\hline $\mathrm{Co}_{72} \mathrm{Ni}_{28}$ & 0.10 & 0.20 & 0.25 & 0.08 & 50 & 0.45 \\
\hline $\mathrm{Co}_{75} \mathrm{Ni}_{25}$ & 0.10 & 0.20 & 0.25 & 0.10 & 50 & 0.45 \\
\hline
\end{tabular}

A Rigaku diffractometer was used to analyze crystalline structure of coatings. The X-ray diffraction (XRD) experiments were performed at $30 \mathrm{~mA}$ and $40 \mathrm{kV}$, with a $2 \theta$ rate of $0.05^{\circ} / 0.5 \mathrm{~s}$ between $5^{\circ}$ and $90^{\circ}$. Surface morphology of the deposited alloys was analyzed with a scanning electron microscope (SEM, JEOL JSM-5500LV, Japan). Inductively coupled plasma (ICP) analyzes were performed to determine elemental composition of the deposited films. A vibrating sample magnetometer (VSM) was used to determine magnetic behavior of the alloys. Magnetic measurements were performed in a magnetic field range from -75 to $+75 \mathrm{kOe}$ at $300 \mathrm{~K}$.

\section{Results and discussion}

Electrochemical characteristics of the four different electrolyte solutions with varying cobalt concentrations were determined in CV studies, as shown in Fig. 1. The scans were initiated at open circuit potential points. During potential scan towards the negative direction, a rapid increase of the cathodic current was observed, especially with increase of Co amount in the solution. Deposition potential of all $\mathrm{Co}-\mathrm{Ni}$ alloys started at $-0.76 \mathrm{~V}$. The anodic scan of alloys shows anodic dissolution at $-0.61 \mathrm{~V}$ vs SCE (Fig. 1). It is suggested that film dissolution occurs under $-0.61 \mathrm{~V}$.

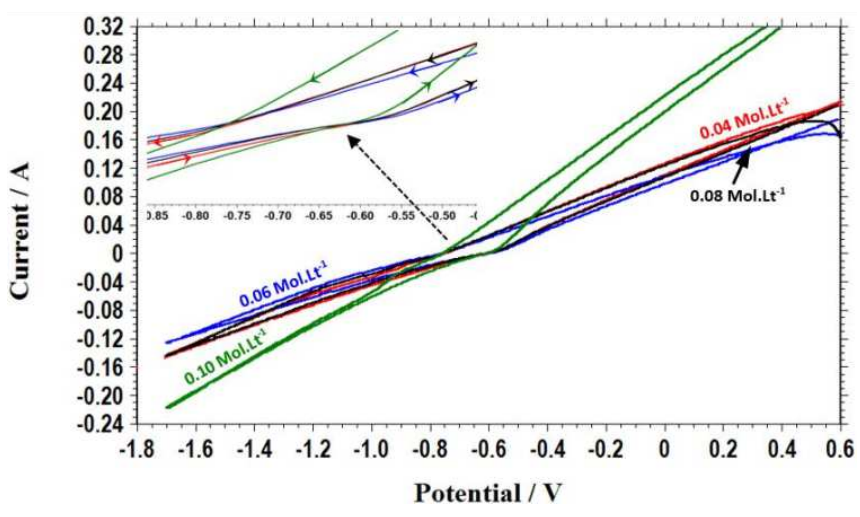

Fig. 1. Cyclic voltammogram for deposition of $\mathrm{Co}-\mathrm{Ni}$ alloys.

The XRD analysis of the deposited Co-Ni alloys has shown that electrodeposited $\mathrm{Co}_{1-x} \mathrm{Ni}_{x}$ alloys have different crystal orientations along (111), (200) and (220) planes, as seen in Fig. 2. Co-Ni Alloys have a broad prominent peak at $44^{\circ}$, corresponding to the (111) plane of face centered cubic (fcc) phase [21]. Different Co concentrations in the electrolyte did not changed crystal orientation but, a slight shift in peak position was observed with the increase of the Co amount, from $2 \theta=44.37^{\circ}$ to $2 \theta=44.56^{\circ}$. Additionally, distance between parallel lattice planes, the $d$-spacing value, had decreased from 2.0401 to $2.0320 \AA$ with the increase of the Co concentration, as seen in Table II.

The dominant crystal orientations of the electrodeposition depend upon the experimental conditions, such as bath composition, deposition potential, and $\mathrm{pH}[19,22]$. Co-Ni alloys with $\mathrm{Ni}$ content higher than $25 \%$ have mostly the fcc phase [23]. The observed fcc phase of the deposited Co-Ni coatings is in accordance with the reported phase diagram of Co-Ni binary alloy [21, 24].

TABLE II

XRD analysis data of the $\mathrm{Co}_{1-x} \mathrm{Ni}_{x}$ alloy films deposited at varying cobalt concentration

\begin{tabular}{c|c|c|c|c|c}
\hline \hline $\mathrm{SN}$ & $\begin{array}{c}2 \theta \\
\text { [deg.] }\end{array}$ & $\begin{array}{c}d \\
{[\AA]}\end{array}$ & $\begin{array}{c}\text { Height } \\
{[\mathrm{cps}]}\end{array}$ & $\begin{array}{c}\text { FWHM } \\
{[\text { deg.] }}\end{array}$ & $\begin{array}{c}\text { Grain size } \\
{[\mathrm{nm}]}\end{array}$ \\
\hline $\mathrm{Co}_{52} \mathrm{Ni}_{48}$ & 44.370 & 2.0401 & 176 & 0.350 & 259 \\
$\mathrm{Co}_{64} \mathrm{Ni}_{36}$ & 44.420 & 2.0378 & 488 & 0.240 & 381 \\
$\mathrm{Co}_{72} \mathrm{Ni}_{28}$ & 44.421 & 2.0378 & 298 & 0.258 & 348 \\
$\mathrm{Co}_{75} \mathrm{Ni}_{25}$ & 44.560 & 2.0320 & 248 & 0.360 & 247
\end{tabular}

Scherer formula, Eq. (1), was used to calculate grain size of the alloys, using values of peak width at the half maximum $\beta[25,26]$. Calculated grain size values of the alloys, as a function of Co concentration are given in Table II. 


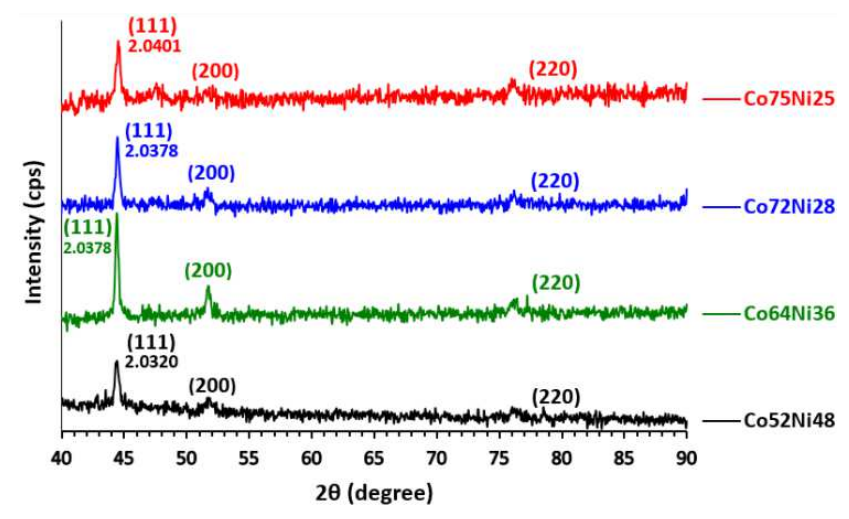

Fig. 2. XRD analysis diagrams of the $\mathrm{Co}_{1-x} \mathrm{Ni}_{x}$ alloy films, deposited at varying cobalt concentrations.

$$
D=\frac{0.9 \lambda}{\beta \cos \theta} .
$$

According to XRD analyzes, Co-Ni alloys have similar crystalline structures. However, a great difference in grain size values was observed with the change of Co concentration. As shown in Table II, grain size has varied between 247 and $381 \mathrm{~nm}$ with the change of the cobalt amount in the electrolyte.

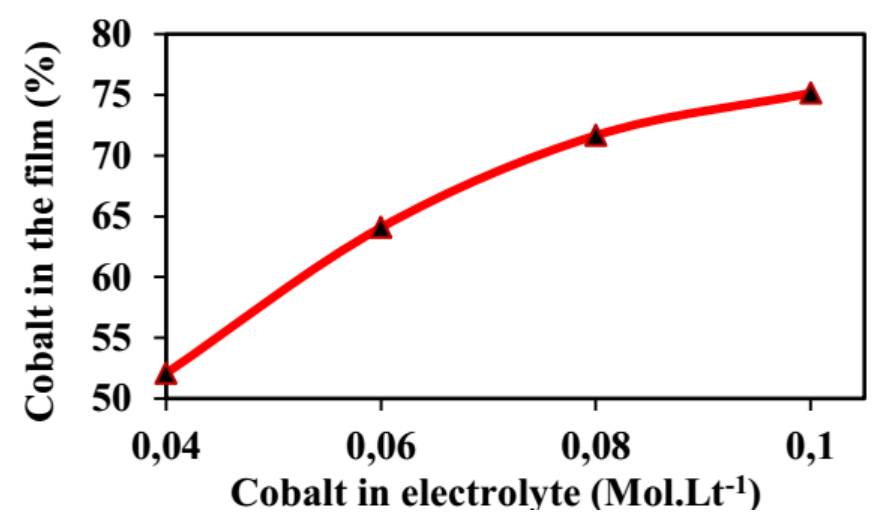

Fig. 3. Changes of film content produced by varying cobalt concentration in the electrolyte.

Results of the ICP analyzes are presented in Fig. 3. Cobalt content in the deposited alloy was increased from $52 \%$ to $76 \%$ with the increase of the Co concentration in the electrolyte from 0.04 to $0.10 \mathrm{M}$. It must be pointed out, that all electrodeposition parameters were the same, with the exception of Co concentration in the electrolyte. The change in the elemental composition of the alloy is completely caused by the change in the electrolyte solution. As expected, the increase of the Co concentration in the solution has resulted in an increase of the Co amount of the deposited Co-Ni alloy [27].

It is reported that Co content in deposited films is always higher than that in electrolyte solution due to the existence of anomalous codeposition. This behavior has been known mainly in codeposition of iron group metals (iron, cobalt and nickel) and zinc with iron-group metals. Increase of $\mathrm{Co}^{2+}$ concentration results in an increase in deposition current. Current contribution from Co is always much higher than that of $\mathrm{Ni}$, even for low $\mathrm{Co}$ concentrations, due to the anomalous codeposition of $\mathrm{Co}$ and $\mathrm{Ni}[28]$.

The surface structure of the alloys was analyzed by scanning electron microscope (SEM), as shown in Fig. 4. According to the SEM images, surface morphology of the Co-Ni coatings is influenced by electrolyte composition. A significantly different surface morphology, with smaller grain sizes, was observed in the alloy with the highest $\mathrm{Ni}$ content, as shown in Fig. 4a. A porous surface structure was observed in this alloy. For the film with the highest Co content, probably an additional precipitation of Co on the Co-Ni alloy layer was observed, as seen in Fig. 4d. SEM images of the films with Co content of $64 \%$ (Fig. 4b) and $72 \%$ (Fig. 4c) displayed similar surface morphology. Calculated grain size values of these films are similar and are smaller, compared to the other films in Fig. 4a and d. It is suggested, that difference in the grain size values has resulted in a different surface structure for $\mathrm{Co}-\mathrm{Ni}$ alloys.
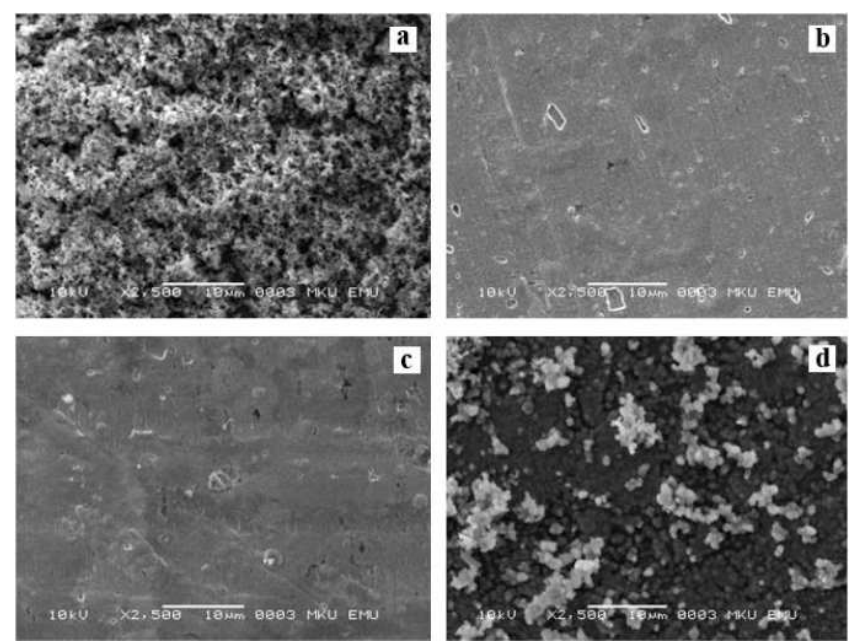

Fig. 4. SEM images of the (a) $\mathrm{Co}_{2} \mathrm{Ni}_{48}$ alloy, (b) $\mathrm{Co}_{64} \mathrm{Ni}_{36}$ alloy, (c) $\mathrm{Co}_{72} \mathrm{Ni}_{28}$ alloy, (d) $\mathrm{Co}_{75} \mathrm{Ni}_{25}$ alloy.

Magnetic properties of the Co-Ni coatings were analyzed with VSM. The saturation magnetization, remanence and coercivity values were measured from the hysteresis loops, as presented in Fig. 5 and b. According to the magnetic analysis results, the coercivity values of the $\mathrm{Co}-\mathrm{Ni}$ films have ranged from 70 to 135 Oe, confirming ferromagnetic behavior of the alloys. Coercivity values of the magnetic materials mainly depend on the particle size and magneto crystalline anisotropy [29-33]. A decrease in grain size results in a decrease in the magnetic domain size, which results in lower coercivity values [34]. It is suggested than in our experiments, the change in the coercivity values is caused by grain size change of the alloys. Co-Ni coatings with larger grain size values have lower coercivity values, as expected [35]. 


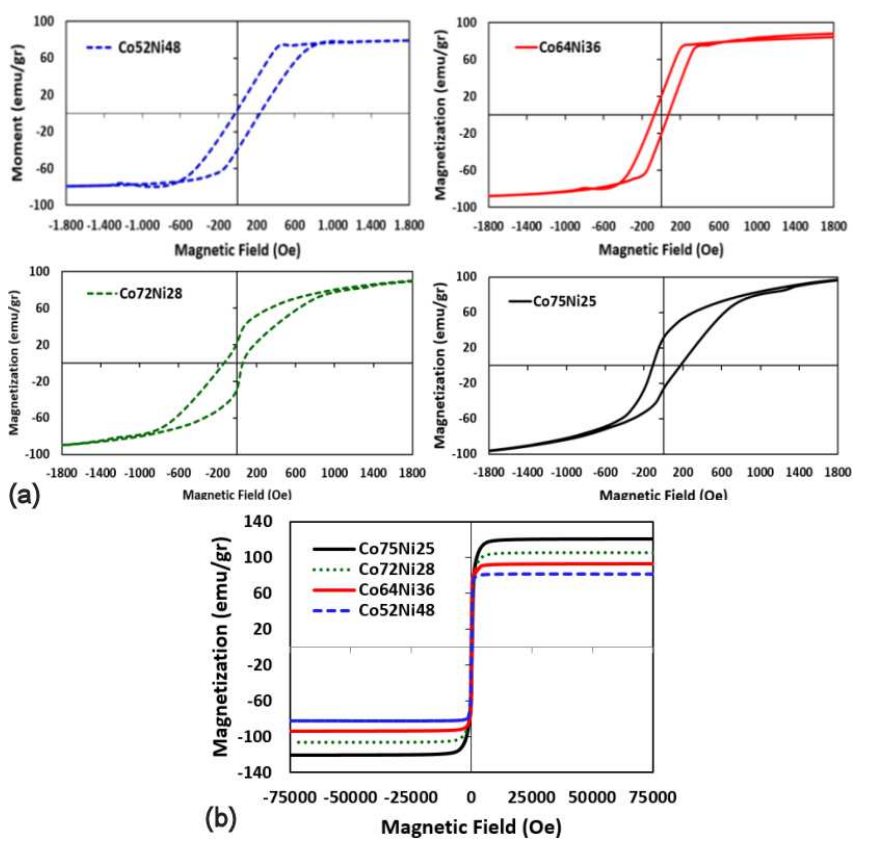

Fig. 5. Magnetization versus applied magnetic field curves of $\mathrm{Co}_{1-x} \mathrm{Ni}_{x}$ alloys (a) between -75000 and +75000 Oe, and (b) between -1800 and +1800 Oe.

As shown in Fig. 5, saturation magnetization $M_{\mathrm{S}}$ values of the coatings decrease from 120.7 to $81.8 \mathrm{emu} / \mathrm{g}$ with the decrease of Co content in the alloy from $75 \%$ to $52 \% . M_{\mathrm{s}}$ value of the bulk Co $\left(1420 \mathrm{emu} / \mathrm{cm}^{3}\right)$ is higher than that of bulk $\mathrm{Ni}\left(480 \mathrm{emu} / \mathrm{cm}^{3}\right)$, which probably has caused the decrease of $M_{\mathrm{S}}$ values of the Co-Ni alloys [36]. Additionally, a decrease in the remanence magnetization $M_{\mathrm{r}}$ values of the samples was observed with the decrease of the Co amount in the alloy. The alloy with lowest Co content of $52 \%$ has a $M_{\mathrm{r}}$ value of $81.8 \mathrm{emu} / \mathrm{g}$, which is the lowest $M_{\mathrm{r}}$ value. The decrease of $M_{\mathrm{s}}$ and $M_{\mathrm{r}}$ values with the decrease of the Co content is due to higher magnetic anisotropy of Co, compared to $\mathrm{Ni}$ [37].

$M_{\mathrm{r}}$ and $M_{\mathrm{S}}$ results indicate that magnetic properties of the Co-Ni coatings have weakened with the decrease of the Co ratio in the alloy, as expected, due to magnetic anisotropy of bulk Co, which is higher than that of $\mathrm{Ni}[38,39]$. It can be said that increase of the Co content results in a superior magnetic behavior of $\mathrm{Co}-\mathrm{Ni}$ alloys.

\section{Conclusions}

Co-Ni alloys were deposited galvonostatically, by electrochemical deposition, onto Al substrates. Effect of the Co content in the electrolyte solution on the physical and magnetic properties of the alloys was investigated. Analysis results indicate that Co content in the solution changes elemental composition of the deposited alloys, which further affects the grain size, elemental composition and magnetic behavior of the alloys. A slight change in surface morphology and crystalline structure of the films was also observed. Experiment results indicate that Co content of the deposited film is related to elemental composition of the electrolyte. Increase in the Co content of the film resulted in higher saturation and remanence magnetization values of the films. Coercivity values of the films have varied with the grain size values of the films. Results of this study show that fabrication of magnetic coatings with desired properties can be performed by controlling the electrodeposition parameters.

\section{Acknowledgments}

The support of this study by the Kilis 7 Aralık University Scientific Research Projects (BAP-2014/02/LTP/05) is gratefully acknowledged.

\section{References}

[1] A. Bai, C.C. Hu, Electrochim. Acta 47, 3447 (2002).

[2] R. Oriňáková, A. Oriňá, G. Vering, I. Talian, R.M. Smith, H.F. Arlinghaus, Thin Solid Films 516, 3045 (2008).

[3] Yu.N. Bekish, S.K. Poznyak, L.S. Tsybulskaya, T.V. Gaevskaya, V.A. Kukareko, A.V. Mazanik, J. Electrochem. Soc. 161, D620 (2014).

[4] Y. Li, H. Jiang, W. Huang, H. Tian, Appl. Surf. Sci. 254, 6865 (2008).

[5] Y.D. Li, H. Jiang, D. Wang, H. Ge, Surf. Coat. Technol. 202, 4952 (2008).

[6] L. Tian, J. Xu, C. Qiang, Appl. Surf. Sci. 257, 4689 (2011).

[7] L. Tian, J. Xu, S. Xiao, Vacuum 86, 27 (2011).

[8] J.V. Arenasa, L.A. Garcia, T. Treeratanaphitak, M. Pritzkera, R.L. Sánchez, R.C. Sierrac, Electrochim. Acta 65, 234 (2012).

[9] İ.H. Karahan, R. Özdemir, B. Erkayman, Appl. Phys. A 113, 459 (2013).

[10] İ.H. Karahan, R. Özdemir, Acta Phys. Pol. A 128, B-427 (2015).

[11] O. Ergeneman, K.M. Sivaraman, S. Pané, E. Pellicer, A. Teleki, A.M. Hirt, M.D. Baró, B.J. Nelson, Electrochim. Acta 56, 1399 (2011).

[12] S. Kirtay, Acta Phys. Pol. A 128, B-90 (2015).

[13] F. Göde, F. Yavuz, I.A. Kariper, Acta Phys. Pol. A 128, B-215 (2015).

[14] M.İ. Coşkun, İ.H. Karahan, T.D. Golden, Surf. Coat. Technol. 275, e1 (2015).

[15] Q.S. Chen, Z.Y. Zhou, G.C. Guo, S.G. Sun, Electrochim. Acta 113, 694 (2013).

[16] C. Liu, F. Su, J. Liang, Surf. Coat. Technol. 292 37 (2016).

[17] U. Sarac, M.C. Baykul, Y. Uguz, J. Supercond. Nov. Magn. 28, 1041 (2015).

[18] R. Özdemir, I.H. Karahan, O. Karabulut, Metall. Mater. Trans. A 47, 5609 (2016).

[19] X. Qiaoa, H. Li, W. Zhaoa, D. Li, Electrochim. Acta 89, 771 (2013).

[20] I.A. Kariper, Ö. Baglayan, F. Göde, Acta Phys. Pol. A 128, B-219 (2015). 
[21] A. Karpuz, H. Kockar, M. Alper, Appl. Surf. Sci. 258, 5046 (2012).

[22] M.Y. Haciibrahimoğlu, M. Bedir, M. Öztaş, C. Cakez, Digest J. Nanomater. Biostruct. 10, 1439 (2015).

[23] S. Samardak, F. Nasirpouri, M. Nadi, E.V. Sukovatitsina, A.V. Ognev, L.A. Chebotkevich, S.V. Komogortsev, J. Magnetism Magnetic Mater. 383, 94 (2015).

[24] S. Sharma, N.S. Gajbhiye, R.S. Ningthoujam, J. Colloid Interface Sci. 351, 323 (2010).

[25] R. Özdemir, I.H. Karahan, Appl. Surf. Sci. 318, 314 (2014).

[26] M. Djamal, Ramli, Khairurrijal, F. Haryanto, Acta Phys. Pol. A 128, B-19 (2015).

[27] E. Gomez, S. Pane, E. Vall, Electrochim. Acta 51, 146 (2005).

[28] L. Tian, J. Xu, C. Qiang, Appl. Surf. Sci. 257, 4689 (2011).

[29] S.B. Waje, M. Hashim, W.D.W. Yusoff, Z. Abbas, Appl. Surf. Sci. 256, 3122 (2010).

[30] V.K. Lakhani, B. Zhao, L. Wang, U.N. Trivedi, K.B. Modi, J. Alloys Compd. 509, 4861 (2011).
[31] D. Nie, C. Xu, H. Chen, Y. Wang, J. Li, Y. Liu, Mater. Lett. 131, 306 (2014).

[32] W. Laslouni, Z. Hamlati, M. Azzaz, Acta Phys. Pol. A 128, B-190 (2015).

[33] W. Laslouni, M. Azzaz, Acta Phys. Pol. A 130, 112 (2016).

[34] A.M. Wahba, N.A. Ali, M.M. Eltabey, Mater. Chem. Phys. 146, 224 (2014).

[35] N. Loudjani, N. Benseba, L. Dekhil, S. Alleg, J.J. Sun, J. Magnetism Magnetic Mater. 323, 3063 (2011).

[36] A. Karpuz, H. Kockar, M. Alper, O. Karaagac, M. Hachismailoglu, Appl. Surf. Sci. 258, 4005 (2012).

[37] W.W. Lin, H. Sang, B. You, Z.S. Hang, Int. J. Modern Phys. B 19, 2562 (2005).

[38] U.B. Sontu, V. Yelasani, V.R.R. Musugu, J. Magnetism Magnetic Mater. 374, 376 (2015).

[39] A.M.P. Sakita, E.C. Passamani, H. Kumar, D.R. Cornejo, C.S. Fugivara, R.D. Noce, A.V. Benedetti, $M a-$ ter. Chem. Phys. 141, 576 (2013). 